\title{
Effects of within-patch heterogeneity on connectivity in pond-breeding amphibians studied by means of an individual-based model
}

\author{
M.-B. Pontoppidan and G. Nachman \\ Section for Ecology and Evolution, Department of Biology, University of Copenhagen, \\ Universitetsparken 15, 2100 Copenhagen, Denmark
}

Correspondence to: M.-B. Pontoppidan (mbp@bio.ku.dk)

Received: 6 September 2012 - Revised: 29 April 2013 - Accepted: 9 May 2013 - Published: 12 June 2013

\begin{abstract}
The metapopulation framework presumes the habitat of a local population to be continuous and homogenous, and patch area is often used as a proxy for population size. Many populations of pond-breeding amphibians are assumed to follow metapopulation dynamics, and connectivity is mostly measured between breeding ponds. However, the habitat of pond-breeding amphibians is not only defined by the pond but, typically, consists of a breeding pond surrounded by clusters of disjoint summer-habitat patches interspersed with an agricultural/semi-urban matrix. We hypothesise that the internal structure of a habitat patch may change connectivity in two ways: (i) by affecting animal movements and thereby emigration and immigration probabilities; and (ii) by affecting habitat quality and population size. To test our hypotheses, we apply a spatially explicit individual-based model of Moor frog dispersal. We find that the realised connectivity depends on internal structure of both the target and the source patch as well as on how habitat quality is affected by patch structure. Although fragmentation is generally thought to have negative effects on connectivity, our results suggest that, depending on patch structure and habitat quality, positive effects on connectivity may occur.
\end{abstract}

1

Within the framework of metapopulations, inter-patch connectivity is modelled as an incidence function measuring the dispersal success between two habitat patches (Moilanen and Nieminen, 2002). The essential components of the incidence function models are emigration and immigration rates. The survival probability during the transit between two patches is modelled as a function of distance. The number of emigrating individuals is assumed to depend on the population size of the donor patch and the probability of an individual actually leaving the patch. Likewise, the number of immigrants depends on the probability that dispersing individuals will find the target patch (Hanski and Simberloff, 1997; Moilanen and Hanski, 2006; Wiens, 1997). Metapopulation theory assumes a patch to constitute a continuous and homogenous habitat area with all the necessary resources needed for the persistence of a local population. Often the size of a subpopulation is assumed to be proportional to the area of the patch it inhabits and the incidence function usually models the emigration and immigration rates as linear functions of donor and target patch area, respectively (Hanski and Simberloff, 1997; Kindlmann and Burel, 2008; Moilanen and Hanski, 2001, 2006; Moilanen and Nieminen, 2002).

However, in some cases, the quality of the occupied habitat patch may be a better predictor of patch carrying capacity (Jaquiéry et al., 2008; Moilanen and Hanski, 1998). One of the factors that may affect patch quality is the degree of habitat fragmentation within the patch. Habitat size as well as access to all necessary resources (landscape complementation) is important for population size and persistence (Dunning et al., 1992). Fragmentation of a habitat patch may reduce the effective area due to negative edge effects as well as increase the distance between resources within the patch. Hence, a fragmented habitat patch may not be able to sustain as large a population as a non-fragmented habitat patch (Dunning et 
al., 1992; Haynes et al., 2007; Johnson et al., 2007; Lehtinen et al., 2003; Ries et al., 2004).

Regional populations of pond-breeding amphibians are frequently considered to be structured as metapopulations (Hels, 2002; Marsh, 2008; Marsh and Trenham, 2001; Smith and Green, 2005). Pond-breeding amphibians need ponds for breeding and development of tadpoles, but otherwise live most of their life in terrestrial habitat (also called summer habitat). Proximity between the required habitat types is vital to population viability (Pope et al., 2000). However, as a consequence of increased landscape fragmentation, the summer habitat of many subpopulations does not form one continuous patch. Typically, a subpopulation of pond-breeding amphibians occupies a landscape consisting of breeding ponds surrounded by fragments of summer habitat interspersed with an agricultural/semi-urban matrix (Hamer and McDonnell, 2008; Hartung, 1991; Pillsbury and Miller, 2008; Pope et al., 2000; Sjögren-Gulve, 1998; Tramontano, 1998). Thus, the metapopulation premise of a continuous and homogenous habitat patch is compromised, which might have consequences for patch connectivity and the way it is measured (Rothermel, 2004).

Numerous studies, empirical as well as modelling, have shown that structure and composition of the habitat matrix can have strong effects on animal movement and dispersal success (e.g. Bender and Fahrig, 2005; Chin and Taylor, 2009; Gustafson and Gardner, 1996; Haynes and Cronin, 2006; Prevedello and Vieira, 2010; Ricketts, 2001; Vandermeer and Carvajal, 2001; Watling et al., 2011). Similar effects may be found within heterogeneous habitat patches, such as those of pond-breeding amphibians. At the core of the habitat patch is the breeding pond surrounded by satellites of summer habitat fragments separated by matrix habitat. The summer habitat fragments within the habitat patch work as a collective, functioning as a filter catching dispersers which will then eventually find their way to the breeding pond. Emigration and immigration probabilities may thus be influenced by the spatial distribution of the summer habitat fragments within the habitat patch.

Dispersal success between habitat patches depends on the emigration rates, immigration rates as well as the dispersal ability of the individual. The internal structure of a habitat patch may therefore change inter-patch connectivity in two ways: (i) by affecting animal movements and thereby emigration and immigration probabilities; and (ii) by affecting habitat quality and thereby the number of dispersers. To test how intra-patch structuring may influence dispersal success and connectivity, we apply a spatially explicit individualbased model of juvenile dispersal in pond-breeding amphibians. The model is part of a larger study aiming at modelling the effect of roads on regional persistence of Moor frog (Rana arvalis) metapopulations (Pontoppidan and Nachman, 2013a, b). With this model, we test the following:
1. Does the distance between the breeding pond and the summer habitat within a habitat patch affect emigration, immigration and dispersal probability?

2. Does the degree of summer habitat fragmentation within a habitat patch affect emigration, immigration and dispersal probability?

3. Do effects of pond distance and summer habitat fragmentation on emigration, immigration and dispersal probability interact?

4. Does the quality of the habitat patch affect inter-patch connectivity?

\section{Methods}

\subsection{Model species}

The model is based on the ecology of Moor frogs but is considered to be a generic model concerning pond-breeding amphibians. Long-distance dispersal in Moor frogs takes place predominantly during the juvenile life stage. Shortly after metamorphosis, the young frogs leave the natal pond and disperse into the surrounding landscape seeking out suitable summer habitat. Dispersal distances are between a few hundred meters up to 1-2 km (Baker and Halliday, 1999; Hartung, 1991; Sinsch, 2006; Vos and Chardon, 1998). The juveniles stay in terrestrial habitat for 2-3 yr until they reach maturity. During early spring, the adults move to the breeding ponds. Soon after breeding, the frogs return to the summer habitat, which lies mostly within a $400 \mathrm{~m}$ radius from the breeding pond. Adult frogs show a high degree of site fidelity and often use the same breeding pond and summer habitat patch from year to year (Hartung, 1991; Loman, 1984, 1994; Semlitsch, 2008; Tramontano, 1998).

\subsection{Model description}

The model description follows the ODD (overview, design concepts, details) protocol for describing individualand agent-based models proposed by Grimm et al. (2006, 2010). Netlogo (Wilensky, 1999) is used as a modelling environment (freely downloadable at http://ccl.northwestern.edu/ netlogo).

\subsubsection{Purpose}

The model considers nine subpopulations of Moor frogs within a spatially explicit landscape matrix and simulates the dispersal of juvenile Moor frogs from their natal ponds. We define the habitat patch of a subpopulation as a complementary habitat patch containing not only the breeding pond but also all summer habitat fragments within the habitat patch boundary $(400 \mathrm{~m})$ of the pond (Fig. 1). The configuration of summer habitat fragments within the habitat patches is determined by two parameters - the number of summer habitat 


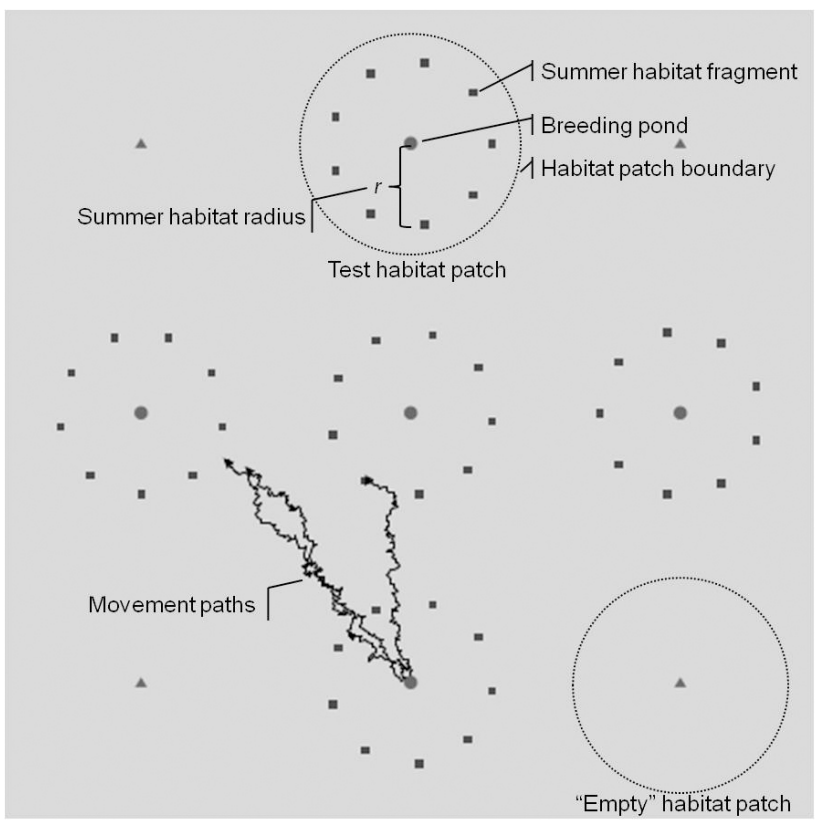

Figure 1. Model landscape with nine habitat patches. The model landscape contains five test (habitat) patches and four empty (habitat) patches (see text). Each test habitat patch is defined by a central breeding pond and fragments of summer habitat within the habitat patch boundary. Distance between breeding pond and summer habitat is denoted $r$. Black sinuous lines are examples of the movement paths of three different frog agents.

fragments $(f)$ and the radius $(r)$ from the breeding pond to the summer habitat fragments. The model evaluates the effect of varying values of $r$ and $f$ on emigration probabilities, immigration probabilities and dispersal success. The model only considers fragmentation of summer habitat within the habitat patch. Successful dispersal requires two events: (1) movement of a juvenile frog to summer habitat outside its natal habitat patch and (2) subsequent movement from the new summer habitat to a nearby breeding pond. In real life the first part starts just after metamorphosis in early summer and lasts until hibernation in the autumn. The second part of the dispersal event takes place in the spring $2.5 \mathrm{yr}$ later. For simplicity, we simulate the two events as if they take place in the same year.

\subsubsection{Entities, state variables, and scales}

The extent of the model landscape is $300 \times 300$ grid cells, and each grid cell represents $10 \mathrm{~m} \times 10 \mathrm{~m}$. Grid cells are defined either as matrix habitat or summer habitat. Each habitat type is associated with a habitat-attraction, $a$ (indicating how willing frogs will be to enter the habitat). Breeding ponds are treated as stationary agents, each pond characterised by a unique id number. Frog agents are characterised by the pond in which they are hatched and the breeding pond they dis- perse to. The simulation runs for 250 time steps, each representing one day.

\subsubsection{Process overview and scheduling}

At the start of the simulation, a landscape with nine subpopulations is constructed according to the parameter settings for $r$ and $f$. In all, 500 frog agents are located at each of the pond agents. During each time-step the following procedures are executed: Settle (evaluates if a frog agent stops dispersing), and Move (movement of dispersing frog agents). The simulation stops at time step 250 and the procedure Output is run.

\subsubsection{Design concepts}

\section{Emergence}

Emigration probabilities, immigration probabilities and dispersal probabilities will emerge as a response to the landscape configuration.

\subsubsection{Adaptation and objectives}

To avoid desiccation and thereby increase survival frog agents are assumed to move in response the moistness of its surroundings. In general, the moister a habitat is the more attractive the habitat is for the frog as indicated by the habitatattraction parameter $a$. Dispersing juvenile Moor frogs have an innate tendency to move away from their natal pond. In the simulation the movement of the frog agents is thus oriented in a random direction away from the pond, and they are not allowed to backtrack.

\section{Sensing}

Frog agents are assumed to be aware of their own statevariables. Frog agents are also aware of the habitat attraction of the grid cells, as well as the identity of the ponds.

\section{Interaction}

There is no interaction between frog agents. Movement decisions of the frog agents depend on the habitat attraction of the neighbouring cells.

\section{Stochasticity}

Which cell to move to is chosen randomly from neighbouring cells with the probability of being chosen weighted by the habitat attraction and the number of neighbouring cells with the same value. If frog agents occupy a cell with summer habitat they will stop dispersing with a certain probability. 
Table 1. Default settings of parameters and the range of parameter values used in the simulations and calculations.

\begin{tabular}{llll}
\hline Parameter & Description & Default & Test values \\
\hline$z$ & Effect of summer habitat fragmentation on habitat quality & 1 & $0.7-2.0$ \\
\hline$A$ & Area of summer habitat in a habitat patch & 0.81 ha (81 cells) & \\
\hline$r$ & $\begin{array}{l}\text { Summer habitat radius, i.e. the distance between pond } \\
\text { and summer habitat within the habitat patch }\end{array}$ & $100 \mathrm{~m}(10$ cells $)$ & $100,200,300 \mathrm{~m}$ \\
\hline$a$ & $\begin{array}{l}\text { Number of summer habitat fragments within the habitat } \\
\text { patch }\end{array}$ & 1 & $1,4,9$ \\
\hline
\end{tabular}

\section{Observation}

At the end of each run the number of frogs settled at each breeding pond and their natal pond is registered.

\subsubsection{Initialization}

A landscape consisting of $300 \times 300$ grid cells is constructed as a torus with nine evenly spaced habitat patches. The four corner habitat patches contain only a breeding pond and do not have any summer habitat fragments. These "empty" habitat patches are used as source patches when computing immigration probabilities of the test habitat patches. The remaining five habitat patches are test patches, in which the number of summer habitat fragments and their distance to the breeding pond are determined by the chosen parameter values for the number of fragments $(f)$ and summer habitat radius $(r)$ (Fig. 1, Table 1). The same set of parameter values is applied to all test patches in the landscape. However, each time a habitat patch is constructed the position of the first fragment is randomly chosen (within a radius of $r$ ) and the remaining summer habitat fragments are then distributed evenly around the pond. Thus, the exact position of the fragments will vary between habitat patches. In each of the five test habitat patches, the total area of the summer habitat sums to 0.81 ha ( 81 cells) irrespective of fragmentation. In all, 500 frog agents are located on each of the nine pond agents, their direction set randomly. We run 100 simulations for every combination of the parameter values for $f$ and $r$ given in Table 1.

\subsubsection{Submodels}

Settle

If a frog agent occupies a summer habitat cell, it has a $50 \%$ probability of settling. Once a frog agent has settled the frog variable BreedingPond is updated with the ID of the breeding pond associated with the summer habitat. The direction of the frog is then set towards the breeding pond.
Move

A frog agent can move to one of its neighbouring cells located within $\pm 110^{\circ}$ from the preferred direction of the frog. Based on the habitat-attraction of the neighbouring cells frogs decide which cell-type they want to move to. The probability of moving into cell $i$ is a function of habitat attraction (a) of the neighbouring cells $(n): p_{i}=\frac{a_{i}}{\sum_{j=1}^{n} a_{j}}$. A uniform pseudorandom number is selected to choose the cell to move to. Once a cell is chosen the frog moves to a random position within the cell. The direction of the frogs does not change. If a frog agent is assigned a breeding pond and comes within a distance of 2 cells from the pond, the frog will jump directly to the pond. Once a frog agent has reached its assigned breeding pond it will cease moving.

\section{Output}

At the end of each simulation the following is registered and computed:

- $N_{H}$ : total number of dispersers from the test patches settled in their natal habitat patch

- $N_{I}$ : total number of dispersers from the "empty" patches settled in the test habitat patches

- $N_{D}$ : total number of dispersers from test patches settled in a test patch other than their natal patch

\subsection{Data analysis}

Based on the observations from the model the following probabilities are computed:

- Mean emigration probability, $P(E)$ $P(E)=\frac{n_{\mathrm{t}} N_{F}-N_{H}}{n_{\mathrm{t}} N_{F}}$, where $n_{\mathrm{t}}$ is the number of test patches and $N_{F}$ the number of dispersers released from a pond.

- Mean immigration probability, $P(I)$ $P(I)=\frac{N_{I}}{n_{\mathrm{t}} n_{\mathrm{e}} N_{F}}$, where $n_{\mathrm{t}}$ is the number of test patches, $n_{\mathrm{e}}$ is the number of "empty" patches and $N_{F}$ the number of dispersers released from a pond. 

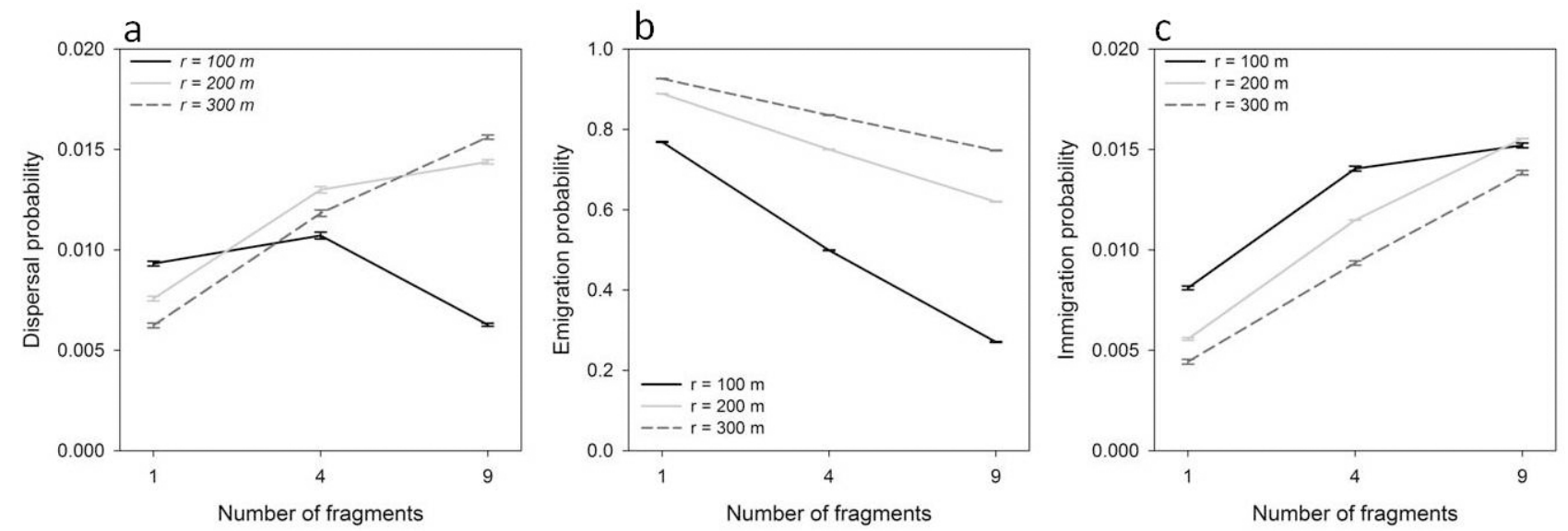

Figure 2. Effect of habitat patch structure on (a) dispersal probability between test patches (b) emigration probability from test patches and (c) immigration probability to test patches. Error bars indicate standard errors.

- Mean dispersal probability, $P(D)$

$P(D)=\frac{N_{D}}{n_{\mathrm{t}}\left(n_{\mathrm{t}}-1\right) N_{F}}, n_{\mathrm{t}}$ is the number of test patches and $N_{F}$ the number of dispersers.

The actual number of emigrants from a source patch will depend on the number of dispersers (which will depend on population size) and the emigration probability. Likewise, the number of immigrants to a target patch will depend on immigration probability and the probability of survival in the new patch. Fragmentation of summer habitat within the habitat patch is expected to have a negative effect on the quality of the habitat patch, so that a habitat patch with highly fragmented summer habitat supports fewer individuals even though the total area is the same (Fahrig, 2003). Thus, fragmentation may affect not only emigration and immigration probabilities but also the quality of source and target patches. The realised emigration rates $(E)$ and immigration rates $(I)$ can then be expressed as

$E=Q_{j} P(E)$

$I=Q_{i} P(I)$,

where $Q$ denotes the quality-adjusted area of the habitat patch. If habitat quality is independent of fragmentation of summer habitat, $Q$ corresponds to $A$, otherwise $Q$ is computed as the total area of summer habitat fragments within the habitat patch weighted by the degree of fragmentation (Jaeger, 2000):

$Q_{i}=\left(\sum_{k=1}^{f} A_{k}^{z}\right), z>0$

where $f$ is the number of summer habitat fragments in habitat patch $i ; A_{k}$ is the area of the $k$-th fragment of summer habitat, and $z$ is a scaling factor indicating the effect of fragmentation on quality. If $z=1$ then $Q_{i}=A_{i}$; if $k>1$ and $z>1$ then $Q_{i}<$ $A_{i}$, and if $k>1$ and $0<z<1$ then $Q_{i}>A_{i}$.
We combine habitat patch fragmentation $(f)$ with summer habitat radius $(r)$ in a fully factorial design, using the following values of $f=4$ and 9 and of $r=100,200$ and 300 . For each of the six combinations of $f$ and $r$, we construct a series of $E$ and $I$ with $z$ values ranging from 0.7 to 2.0, using the emigration and immigration probabilities estimated by the model. We transform the $E$ and $I$ values into a relative emigration rate $\left(R_{\mathrm{E}}\right)$ and a relative immigration rate $\left(R_{\mathrm{I}}\right)$, respectively, by dividing with the corresponding unadjusted emigration and immigration rates found when $f=1$ and $r=100$, i.e. $R_{\mathrm{E}}=E(f, r) / A \cdot P(E)(f=1, r=100)$. For any given combination of summer habitat radius and habitat fragmentation, this value expresses the relative effect habitat quality has on emigration and immigration rates.

We use a two-way ANOVA to test for the effect of the number of summer habitat fragments within the habitat patch and their distance to the breeding pond on emigration, immigration and dispersal probability.

\section{Results}

Mean dispersal probability between test patches is clearly affected by the structure of the habitat patches, showing strong interactions between summer habitat radius $(r)$ and summer habitat fragmentation $(f)\left(F_{8,891}=719, p<0.001\right)$ (Fig. 2a, Table 2). Summer habitat radius has a positive effect on the dispersal probability between highly fragmented habitat patches; however, the effect is negative between nonfragmented patches. Moreover, fragmentation of summer habitat in habitat patches has a positive effect on dispersal probability, especially between habitat patches with long summer habitat radius.

Mean emigration probability is negatively affected by summer habitat fragmentation and positively affected by summer habitat radius within source patches $\left(F_{8,891}=\right.$ $58710, p<0.001)$. Effect of fragmentation is strongest when 
Table 2. Anova test results. Effect of summer habitat radius $(r)$ and number of summer habitat fragments $(f)$ and their interaction on emigration probability, immigration probability and dispersal probability.

\begin{tabular}{|c|c|c|c|c|c|c|c|c|c|c|}
\hline \multirow[t]{2}{*}{ Source } & \multirow[t]{2}{*}{ df } & \multicolumn{3}{|c|}{ Emigration probability } & \multicolumn{3}{|c|}{ Immigration probability } & \multicolumn{3}{|c|}{ Dispersal probability } \\
\hline & & SS & $F$ & $p$ & SS & $F$ & $p$ & SS & $F$ & $p$ \\
\hline$f$ & 2 & 14.94 & 101326 & $<0.001$ & 0.0120 & 5245 & $<0.001$ & 0.0036 & 1096 & $<0.001$ \\
\hline$r$ & 2 & 16.95 & 114980 & $<0.001$ & 0.0016 & 692 & $<0.001$ & 0.0015 & 438 & $<0.001$ \\
\hline$f \cdot r$ & 4 & 2.73 & 9267 & $<0.001$ & 0.0004 & 87 & $<0.001$ & 0.0045 & 670 & $<0.001$ \\
\hline Error & 891 & 0.07 & & & 0.0010 & & & 0.0015 & & \\
\hline Corrected Total & 899 & 34.69 & & & 0.0150 & & & 0.0110 & & \\
\hline
\end{tabular}

summer habitat radius is short, while the effect of radius is stronger in more fragmented habitat patches. The highest emigration probability is found in non-fragmented habitat patches with long summer habitat radius. Lowest emigration probability is found in fragmented habitat patches with short summer habitat radius (Fig. 2b, Table 2).

Fragmentation of summer habitat in the habitat patches promotes immigration probability. Radius between breeding pond and summer habitat has a weak negative effect $\left(F_{8,891}=1527, p<0.001\right)($ Fig. 2c, Table 2). The effect of fragmentation is strongest when summer habitat radius is short, while the effect of summer habitat radius on immigration probability is less pronounced in very fragmented habitat patches.

The relative emigration rate $R_{\mathrm{E}}$ and immigration rate $R_{\mathrm{I}}$ evaluates the effect of habitat quality on emigration and immigration rates compared to the reference scenario (i.e. $f=1, r=100 \mathrm{~m}$ ). The emigration probability is negatively affected by summer habitat fragmentation in habitat patches, which again is reflected in the $z$ thresholds (Fig. 3a). Here most threshold values for emigration rates are less than 1 , indicating that the negative effect of patch structure on emigration probability only can be counterbalanced if summer habitat fragmentation has a positive effect on habitat quality. Immigration probability is positively affected by summer habitat fragmentation and, conversely, the threshold-values for immigration rates are greater than 1, ranging from ca 1.1 to ca 1.7 depending on degree of summer habitat fragmentation and pond distance (Fig. 3b). This suggests that the positive effect of fragmentation on immigration probability will only be neutralised when habitat quality is strongly reduced by fragmentation.

\section{Discussion}

Inter-patch distance is widely recognised as a key factor for dispersal success (Goodwin and Fahrig, 2002; Gustafson and Gardner, 1996; Hanski, 1998; Prevedello and Vieira, 2010). All else being equal, increasing inter-patch distances means more time spent in an inhospitable matrix habitat, with consequently higher mortality rates. In our model, we keep the number of habitat patches, their distribution as well as interpatch distance constant. Thus, if no other factors interfered we would expect dispersal success to be the same between all simulations. Our results show that this is not the case; dispersal success varies depending on the structure of the habitat patches. Hence, the distribution of summer habitat fragments within habitat patches is important for emigration and immigration probabilities.

Emigration probability depends on the chances of not being retained by summer habitat within the natal (habitat) patch. This probability increases the further away from the breeding pond the summer habitat is found and decreases the more fragmented the summer habitat is. Conversely, the proportion of dispersers that are retained and thus return to their natal pond increases with fragmentation of summer habitat and decreases with summer habitat radius. The opposite pattern is found when looking at immigration, i.e. the probability of a dispersing juvenile finding summer habitat in a new patch. Immigration probability increases with fragmentation of summer habitat but decreases with summer habitat radius. Thus, the combination of effects creates a complex pattern of dispersal success, depending on the structure of source and target patches.

Bowman et al. (2002) suggest that for non-searching dispersers, immigration probability will be proportional to the linear dimensions of the target patch. In a simulation study, Pfenning et al. (2004) found the immigration rate to increase with perimeter-to-area ratio; dispersers using correlated (straight) walk having the strongest effect. The dispersal patterns found in this study can be explained by similar statistical reasoning. As fragmentation of summer habitat increases, the perimeter: area ratio of summer habitat fragments also increases. In this study, the linear dimension of summer habitat fragments increases from ca $100 \mathrm{~m}$ to ca. $270 \mathrm{~m}$ as the summer habitat gets more fragmented. Increasing summer habitat radius causes the gaps between the summer habitat fragments to become wider. Consequently, the probability of dispersers encountering summer habitat becomes relatively smaller as summer habitat radius increases. The effects of the $p: a$ ratio and gab size will interact. At any given summer habitat radius, the probability of finding 

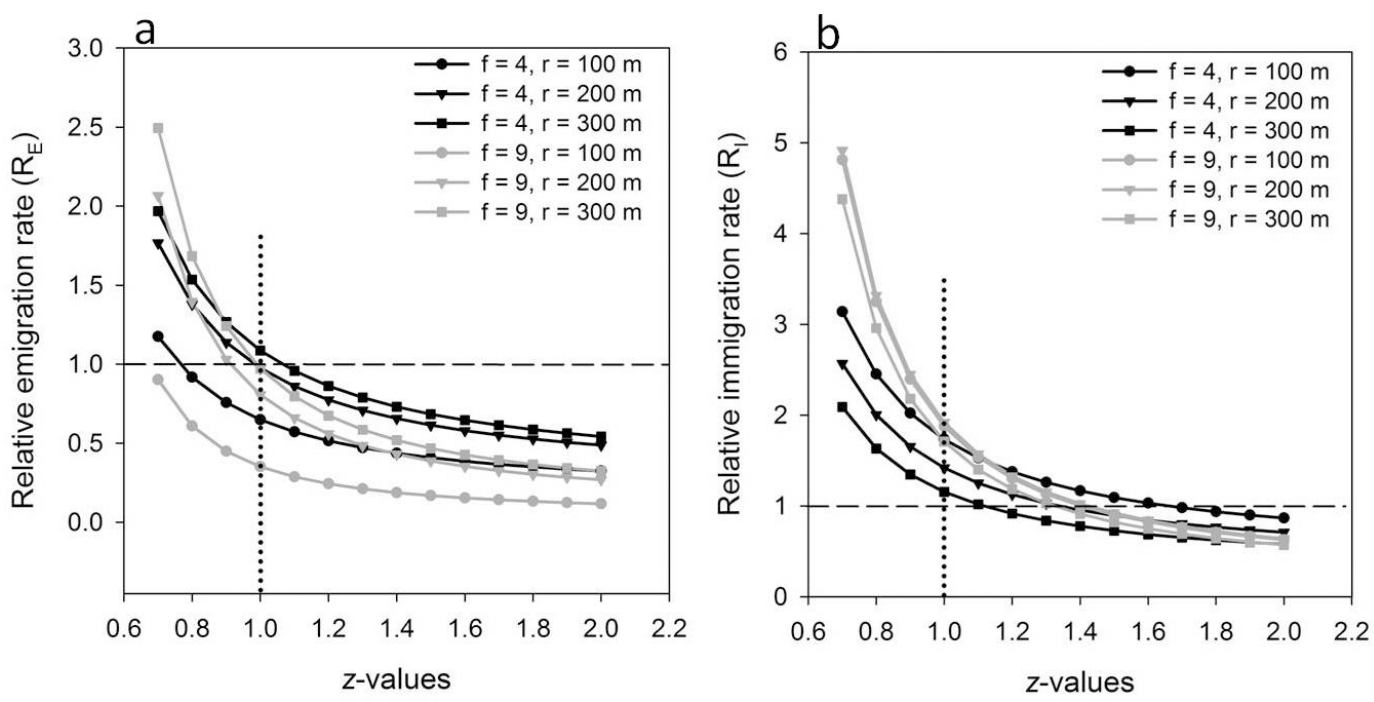

Figure 3. Relative effect of habitat quality on (a) emigration rates and (b) immigration rates for different landscape scenarios. At a $z$ value equal to 1 (dotted, vertical line), the effective area equals the real area. $R$ values along this line represent the relative effect a particular patch structure has on emigration or immigration rates. When $R=1$ (dashed, horizontal line), the quality weighted rates for a given landscape corresponds to the reference rates (i.e. scenario with $f=1, d=100$ ). The $z$ value of the intercept between the dashed line and a given curve can be interpreted as the threshold at which the habitat quality is low enough to shift a positive effect on emigration or immigration rates into a negative effect.

summer habitat patches will be proportional to the ratio between the linear dimension of summer habitat patches and gaps. This is the same whether the movement is outbound or inbound. Successful dispersal will depend on the probability of a disperser to avoid summer habitat within the natal patch and the probability of finding summer habitat in the target patch.

Exchange of individuals between habitat patches is important for the persistence of a regional population of pondbreeding amphibians (Marsh and Trenham, 2001). Our results suggest that fragmentation of summer habitat within target habitat patches can have positive effects on dispersal success. However, intra-patch structure may also affect the persistence of the local population; habitat fragmentation is in general thought to have a negative effect on habitat quality (Jaeger, 2000; Pillsbury and Miller, 2008; Vos and Chardon, 1998). The same spatial distribution that promotes regional persistence, thus, seems to impair local persistence. The results suggest that adjusting emigration and immigration rates for the effect of fragmentation on habitat quality may offset the positive effects of fragmentation on dispersal success. This, however, will depend on how strongly fragmentation of summer habitat is assumed to affect habitat quality (i.e. the $z$ value) and the structure of the habitat patch. We find that the threshold values in habitat patches very much depend on patch structure. For some landscapes a downscaling of effective area to 0.48 ha is needed before positive effects of summer habitat fragmentation on immigrations rates are turned negative. Emigration rates are negatively affected by summer habitat fragmentation and this pattern is not changed when adjusting for habitat quality, unless we assume positive quality effects of fragmentation and up-scale effective area to 2 ha.

Like summer habitat fragmentation, summer habitat radius may affect habitat quality. In the breeding season, mature frogs move between the summer habitat and the breeding pond. Thus, longer distances through the matrix may induce higher mortality. Furthermore, breeding ponds with high quality summer habitat in the immediate surroundings tend to have higher juvenile survival and thus more dispersers (Hamer and McDonnell, 2008; Puglis and Boone, 2012; Todd and Rothermel, 2006). For the sake of simplicity, we have chosen not to incorporate these effects on habitat quality in the model. We expect, though, that the negative effect a long summer habitat radius will have on local population size, at least partly, will negate the positive effect on dispersal success.

In this model, dispersers move through a homogenous matrix and habitat specific survival is therefore not considered. Dispersers are just "killed" if they have not found summer habitat and a breeding pond at the end of the simulation. However, in a heterogeneous landscape dispersers will experience different mortality rates and the realised emigration, immigration and dispersal rates will also depend on the variation in survival probability between habitat types. 


\section{Conclusion}

To our knowledge, this is the first study looking at the effect of intra-patch structure on dispersal success. We find that the realised emigration and immigration rates depend on internal structure of the habitat patch as well as on how habitat quality is affected by patch structure. Although, fragmentation of summer habitat is generally thought to have negative effects on dispersal success, our results suggest that, depending on patch structure and habitat quality, positive effects on dispersal may occur. Measures of connectivity are frequently used in conservation planning and studies on pond breeding amphibian often use distance between breeding ponds as a measure of dispersal ability. This study emphasises that complex interactions between individuals and landscape elements in both source and target patches determine the dispersal success between habitat patches.

Acknowledgements. This study is part of a Ph.D.-project funded by the Danish Road Directorate. We thank Uta Berger and Volker Grimm for valuable feedback on the model ODD. We also thank Ulrich Sinsch and two anonymous reviewers for insightful comments to the manuscript.

Edited by: R. Brandl

Reviewed by: U. Sinsch and one anonymous referee

\section{References}

Baker, J. M. R. and Halliday, T. R.: Amphibian colonization of new ponds in an agricultural landscape, Herpetol. J., 9, 55-63, 1999.

Bender, D. J. and Fahrig, L.: Matrix structure obscures the relationship between interpatch movement and patch size and isolation, Ecology, 86, 1023-1033, 2005.

Bowman, J., Cappuccino, N., and Fahrig, L.: Patch size and population density: the effect of immigration behavior, Conserv. Ecol., 6, 9, 2002.

Chin, K. S. and Taylor, P. D.: Interactive effects of distance and matrix on the movements of a peatland dragonfly, Ecography, 32, 715-722, doi:10.1111/j.1600-0587.2009.05744.x, 2009.

Dunning, J. B., Danielson, B. J., and Pulliam, H. R.: Ecological processes that affect populations in complex landscapes, Oikos, 65, 169-175, doi:10.2307/3544901, 1992.

Fahrig, L.: Effects of habitat fragmentation on biodiversity, Annu. Rev. Ecol. Evol. S., 34, 487-515, doi:10.1146/annurev.ecolsys.34.011802.132419, 2003.

Goodwin, B. J. and Fahrig, L.: How does landscape structure influence landscape connectivity?, Oikos, 99, 552-570, doi:10.1034/j.1600-0706.2002.11824.x, 2002.

Grimm, V., Berger, U., Bastiansen, F., Eliassen, S., Ginot, V., Giske, J., Goss-Custard, J., Grand, T., Heinz, S. K., Huse, G., Huth, A., Jepsen, J. U., Jorgensen, C., Mooij, W. M., Muller, B., Pe'er, G., Piou, C., Railsback, S. F., Robbins, A. M., Robbins, M. M., Rossmanith, E., Ruger, N., Strand, E., Souissi, S., Stillman, R. A., Vabo, R., Visser, U., and DeAngelis, D. L.: A standard protocol for describing individual-based and agent-based models, Ecol.
Model., 198, 115-126, doi:10.1016/j.ecolmodel.2006.04.023, 2006.

Grimm, V., Berger, U., DeAngelis, D. L., Polhill, J. G., Giske, J., and Railsback, S. F.: The ODD protocol: A review and first update, Ecol. Model., 221, 2760-2768, doi:10.1016/j.ecolmodel.2010.08.019, 2010.

Gustafson, E. J. and Gardner, R. H.: The effect of landscape heterogeneity on the probability of patch colonization, Ecology, 77, 94-107, doi:10.2307/2265659, 1996.

Hamer, A. J. and McDonnell, M. J.: Amphibian ecology and conservation in the urbanising world: A review, Biol. Conserv., 141, 2432-2449, doi:10.1016/j.biocon.2008.07.020, 2008.

Hanski, I.: Metapopulation dynamics, Nature, 396, 41-49, doi:10.1038/23876, 1998.

Hanski, I. and Simberloff, D.: The Metapopulation Approach, Its history, Conceptual domain, and Application to Conservation, in: Metapopulation Biology: ecology, genetics, and evolution, edited by: Hanski, I. and Gilpin, M. E., Academic Press, Inc., 1997.

Hartung, H.: Untersuchung zur terrestrischen Biologie von Populationen des Moorfrosches (Rana arvalis NILSSON 1842) unter besonderer Berücksichtigung der Jahresmobilität, Ph.D. thesis, Fachbereiches Biologie, Universität Hamburg, Hamburg, 1991.

Haynes, K. J. and Cronin, J. T.: Interpatch movement and edge effects: the role of behavioral responses to the landscape matrix, Oikos, 113, 43-54, 2006.

Haynes, K. J., Diekotter, T., and Crist, T. O.: Resource complementation and the response of an insect herbivore to habitat area and fragmentation, Oecologia, 153, 511-520, doi:10.1007/s00442007-0749-4, 2007.

Hels, T.: Population dynamics in a Danish metapopulation of spadefoot toads Pelobates fuscus, Ecography, 25, 303-313, doi:10.1034/j.1600-0587.2002.250307.x, 2002.

Jaeger, J. A. G.: Landscape division, splitting index, and effective mesh size: new measures of landscape fragmentation, Landscape Ecol., 15, 115-130, 2000.

Jaquiéry, J., Guélat, J., Broquet, T., Berset-Brändli, L., Pellegrini, E., Moresi, R., Hirzel, a. H., and Perrin, N.: Habitat-quality effects on metapopulation dynamics in greater white-toothed shrews, Crocidura russula, Ecology, 89, 2777-2785, 2008.

Johnson, J. R., Knouft, J. H., and Semlitsch, R. D.: Sex and seasonal differences in the spatial terrestrial distribution of gray treefrog (Hyla versicolor) populations, Biol. Conserv., 140, 250258, doi:10.1016/j.biocon.2007.08.010, 2007.

Kindlmann, P. and Burel, F.: Connectivity measures: a review, Landscape Ecol., 23, 879-890, doi:10.1007/s10980-008-9245-4, 2008.

Lehtinen, R. M., Ramanamanjato, J. B., and Raveloarison, J. G.: Edge effects and extinction proneness in a herpetofauna from Madagascar, Biodivers. Conserv., 12, 1357-1370, doi:10.1023/a:1023673301850, 2003.

Loman, J.: Density and survival of Rana arvalis and Rana temporaria, Alytes, 3, 125-134, 1984.

Loman, J.: Site tenacity, within and between summers, of Rana arvalis and Rana temporaria, Alytes, 12, 15-29, 1994.

Marsh, D.: Metapopulation viability analysis for amphibians, Anim. Conserv., 11, 463-465, doi:10.1111/j.1469-1795.2008.00223.x, 2008.

Marsh, D. M. and Trenham, P. C.: Metapopulation dynamics and amphibian conservation, Conserv. Biol., 15, 40-49, 2001. 
Moilanen, A. and Hanski, I.: Metapopulation dynamics: Effects of habitat quality and landscape structure, Ecology, 79, 2503-2515, 1998.

Moilanen, A. and Hanski, I.: On the use of connectivity measures in spatial ecology, Oikos, 95, 147-151, doi:10.1034/j.16000706.2001.950116.x, 2001.

Moilanen, A. and Hanski, I.: Connectivity and metapopulation dynamics in highly fragmented landscapes, in: Connectivity Conservation, edited by: Crooks, K. R. and Sanjayan, M., Cambridge University Press, 2006.

Moilanen, A. and Nieminen, M.: Simple connectivity measures in spatial ecology, Ecology, 83, 1131-1145, 2002.

Pfenning, B., Hovestadt, T., and Poethke, H. J.: The effect of patch constellation on the exchange of individuals between habitat-islands, Ecol. Model., 180, 515-522, doi:10.1016/j.ecolmodel.2004.04.035, 2004.

Pillsbury, F. C. and Miller, J. R.: Habitat and landscape characteristics underlying anuran community structure along an urban-rural gradient, Ecol. Appl., 18, 1107-1118, doi:10.1890/07-1899.1, 2008.

Pontoppidan, M.-B. and Nachman, G.: Spatial Amphibian Impact Assessment - a management tool for assessment of road effects on regional populations of Moor frogs (Rana arvalis), Nat. Conserv., in press, 2013a.

Pontoppidan, M.-B. and Nachman, G.: Changes in behavioural responses to infrastructure affect local and regional connectivity a simulation study on pond breeding amphibians, Nat. Conserv., in press, 2013b.

Pope, S. E., Fahrig, L., and Merriam, N. G.: Landscape complementation and metapopulation effects on leopard frog populations, Ecology, 81, 2498-2508, 2000.

Prevedello, J. A. and Vieira, M. V.: Does the type of matrix matter? A quantitative review of the evidence, Biodivers. Conserv., 19, 1205-1223, doi:10.1007/s10531-009-9750-z, 2010.

Puglis, H. J. and Boone, M. D.: Effects of terrestrial buffer zones on amphibians on golf courses, PLoS ONE, 7, e39590, doi:10.1371/journal.pone.0039590, 2012.

Ricketts, T. H.: The matrix matters: Effective isolation in fragmented landscapes, Am. Nat., 158, 87-99, doi:10.1086/320863, 2001.

Ries, L., Fletcher, R. J., Battin, J., and Sisk, T. D.: Ecological responses to habitat edges: Mechanisms, models, and variability explained, Annu. Rev. Ecol. Evol. S., 35, 491-522, doi:10.1146/annurev.ecolsys.35.112202.130148, 2004.
Rothermel, B. B.: Migratory success of juveniles: A potential constraint on connectivity for pond-breeding amphibians, Ecol. Appl., 14, 1535-1546, 2004.

Semlitsch, R. D.: Differentiating migration and dispersal processes for pond-breeding amphibians, J. Wildlife Manage., 72, 260267, doi:10.2193/2007-082, 2008.

Sinsch, U.: Orientation and navigation in Amphibia, Mar. Freshw. Behav. Phy., 39, 65-71, doi:10.1080/10236240600562794, 2006.

Sjögren-Gulve, P.: Spatial movement patterns in frogs: Targetoriented dispersal in the pool frog, Rana lessonae, Ecoscience, 5, 31-38, 1998.

Smith, M. A. and Green, D. M.: Dispersal and the metapopulation paradigm in amphibian ecology and conservation: are all amphibian populations metapopulations?, Ecography, 28, 110-128, 2005.

Todd, B. D. and Rothermel, B. B.: Assessing quality of clearcut habitats for amphibians: Effects on abundances versus vital rates in the southern toad (Bufo terrestris), Biol. Conserv., 133, 178185, doi:10.1016/j.biocon.2006.06.003, 2006.

Tramontano, R.: The post-breeding migration of the European common frog, Rana temporaria: effects of landscape structure and seasonal weather, Lund University, Lund, 1998.

Vandermeer, J. and Carvajal, R.: Metapopulation dynamics and the quality of the matrix, Am. Nat., 158, 211-220, doi:10.1086/321318, 2001.

Vos, C. C. and Chardon, J. P.: Effects of habitat fragmentation and road density on the distribution pattern of the moor frog Rana arvalis, J. Appl. Ecol., 35, 44-56, 1998.

Watling, J. I., Nowakowski, A. J., Donnelly, M. A., and Orrock, J. L.: Meta-analysis reveals the importance of matrix composition for animals in fragmented habitat, Global Ecol. Biogeogr., 20, 209-217, doi:10.1111/j.1466-8238.2010.00586.x, 2011.

Wiens, J. A.: Metapopulation Dynamics and Landscape Ecology, in: Metapopulation Biology: ecology, genetics, and evolution, edited by: Hanski, I. and Gilpin, M. E., Academic Press, Inc., 1997.

Wilensky, U.: NetLogo, Center for Connected Learning and Computer-Based Modeling, Northwestern University, Evanston, IL, http://ccl.northwestern.edu/netlogo, 1999. 